\begin{tabular}{c|c}
$F$ & UC-NRLF \\
1480 & $\|H\| H\|H\| H \| H$
\end{tabular}$\|$

$\frac{m}{n}$
$n$
$n$ 
" 


\section{THE ADAPTABILITY OF THE WHITE MAN TO TROPICAL AMERICA}

By ELLSWORTH HUNTINGTON, Ph.D.

Assistant Professor of Geography, Yale University

Reprinted from The Journal of Rice Development, Vol. 5 , No 2, October, 1914 


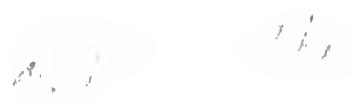

$$
\begin{aligned}
& \because \div \quad \cdot \quad \therefore \cdots \\
& \therefore \because \because \because \because \cdots \div \cdots
\end{aligned}
$$


Reprinted from The Journal of Race Development. .

Vol. 5, No. 2, Octónel, 1914

\section{THE ADAPTABILITY OF THE WHITE MAN TO TROPICAL AMERICA}

\section{By Ellsworth Huntington, Ph.D., Assistant Professor of Geography, Yale University}

The tropical portions of America and Africa, as every one knows, are the richest unexploited regions in the world. If ever they are to be developed the work must apparently be done by people of European origin, for the native races seem incapable of doing it alone, and Europe and America are scarcely willing to leave the task to Asiatics. Yet in spite of innumerable attempts during the past four hundred years the problem of the adaptation of the white races to a tropical environment still remains one of the most serious that has ever confronted mankind. Shall the white man forever be an outsider, a mere exploiter, or shall he become a permanent denizen of the regions which he develops? This question has been debated so often and so vainly that the present discussion would scarcely be warranted, were it not for two reasons. In the first place, certain phases of the subject do not seem to have received due attention; and, in the second place, recent investigations suggest a new way whereby at least a part of the truth may be discovered. The question to be solved is briefly this: Modern medical science is rapidly enabling the white man to combat the diseases which have been so deadly in tropical regions. In other ways, also, we are learning to overcome the disadvantages of a tropical environment. Does this give us ground for believing that races of European origin can dwell permanently within the tropics and retain not only their health, but the physical energy and mental and moral vigor which have enabled them to dominate the world? The success which has thus far been attained in this attempt can scarcely be considered encouraging, but is that any reason for discouragement in the future? 
In order to make our discussion concrete, let us limit it to South and Central America, and to that portion which lies within twenty degrees of the equator. By taking this latitude as a boundary we exclude Rio de Janeiro and the southern part of Brazil, where most of the strength of that country lies, although far the greater portion of the actual area lies within our boundaries. We may also exclude the City of Mexico, although it lies slightly less than $20^{\circ}$ from the equator. This leaves southern Mexico, Central America, Colombia, Venezuela, Guiana, Ecuador, Peru, Bolivia, and all except the most progressive part of Brazil. These countries have an area of nearly 5,000,000 square miles, or fully one and one-half times as much as the United States. The population is estimated at only $35,000,000$ or $40,000,000$. In this vast area the number of genuine white men, that is, people of pure European race, is only a few million, and most of these are confined to the seacoast, or to relatively small areas among the mountains. An area of 4,000,000 square miles is today practically untouched by the white man, except when he comes temporarily in the character of an exploiter, or as an official of one of the South American republics. Nowhere else in the world does there appear to be so vast an area which at the same time contains so few people, and has such enormous latent wealth. It is no wonder that travelers grow enthusiastic over it, and that those who believe that through the elimination of disease the white man will be enabled to live here, are convinced that a wonderful future is in store for it. This is probably true, but before these countries can rival those of temperate regions we must know vastly more than is now the case as to how man is influenced by his environment. Today the most advanced regions within the limits here defined are typified by southern Mexico, with its happy-go-lucky (peasants and banditti; Guatemala, with its unchanging, stolid Indians, who literally will not work so long as they have anything to eat; Nicaragua and Honduras, with their constant revolutions; Ecuador, with its callous indifference to the direst plagues in its own ports, and Peru, where in spite of the culture of the small number of Spanish inhabitants, 
the vast majority are utterly illiterate. We are apt to blame the people of these tropical countries for their backward condition, but in that we sadly wrong them. They are not backward because they want to be so, and they would gladly make progress if they could. Something holds them back against their will, and we who have the good fortune not to be thus held back can do no greater service either to ourselves or to them than to discover exactly what that something is. In order to do this, the first requisite is a clear understanding of our problem. Therefore it will be well to review some of the conditions which for ages have acted as handicaps to every race whose lot has been cast in tropical America. Let us first consider the effect of these conditions upon primitive people, and then see how far there is a reasonable prospect that the white man can overcome them. Some of the conditions which we shall consider are familiar, and have been much discussed, but others have received relatively little attention.

To begin with one of the most familiar topics, the ease with which a living can be made is constantly cited as one of the reasons for the backwardness of tropical people. The importance of this among lower races can scarcely be questioned. If the traditional palm-tree will support a family, the members of that family are not likely to work, except under some unusual impulse. The necessity to provide for a cold winter, or for a long dry season, does not trouble them. Clothing may be desirable because it is the fashion, and because it serves as a means of adornment, but it is not a real necessity. A warm house is equally unnecessary, and a shelter from the rain can quickly be made with a few poles and palm leaves. Where such conditions prevail, progress is almost out of the question, since there is no stimulus - nothing to promote ambition or energy. In Central and South America, however, this most exploited hindrance of equatorial countries seems to be of relatively small importance. In certain regions, to be sure, the means of supporting life can be obtained with great ease, but this is limited to restricted areas, chiefly near the coast, or on the slopes of the mountains. Elsewhere, which means in by 
far the larger part of tropical America, the case is quite different. Although a small number of people can support a precarious existence in primitive fashion, their lot is by no means easy, and the population cannot become dense, nor can it greatly advance in civilization, because as yet no means have been devised whereby a large number of people can procure a living.

This is due to the conditions of agriculture. The ease, or rather the difficulty, with which agriculture can be carried on in tropical countries is greatly misunderstood. The ordinary traveler sees the luxuriant vegetation and infers that crops can be raised with great ease. Noting, however, that in the few places where fields are cultivated they are usually full of stumps, bushes and large weeds, he promptly accuses the natives of shiftlessness. He sees too that a field is cultivated this year and abandoned next, and proceeds to berate the natives for lack of persistence. He fails to realize that throughout large portions of tropical America agriculture is so difficult that even the white man has not yet learned to carry it on. He may raise bananas and coffee in a few limited areas, but he does not do this in the worst places. Moreover these crops are much easier to raise than are the staple crops which have to be planted every year. I do not mean by this that he could not raise the staple crops, provided fevers did not exclude him from large areas, but merely that he has not yet done it. In the regions to which I refer, that is, such places as large portions of the Amazon Basin, rain falls at almost all times of the year, and the dry season is so short, or at least so interrupted by showers that the forests always remain damp, and vegetation grows with extraordinary luxuriance. Any one who has tried to keep a garden free from weeds during a rainy summer will appreciate the difficulty, but his task is incomparably easier than that of the denizens of the tropics, for he has the winter to help him. Moreover he can cultivate his land every year instead of intermittently.

As an example of the difficulties of agriculture, let us take the Pacific slope of Guatemala, which is by no means the wettest part of the country. I traversed the region in 
March, 1913, in the middle of the dry season. The people had recently finished the work of making the season's clearings. The traveler in such a region wonders at first why everyone seems to be clearing new fields. The reasonable thing would seem to be to burn the corn stalks and weeds, and cultivate the old fields again, but this is not done. After a field has once been cultivated it is allowed to lie fallow for four years. The first crop is abundant and requires a relatively small amount of labor, but if the same feld is planted a second time, the crop is very scanty. Apparently the soil is quickly exhausted, perhaps because of rapid weathering under the influence of constant heat, and rapid leaching because of constant moisture, or perhaps because of certain bacteria which flourish in tropical climates and break up the nitrogenous elements of the soil thus destroying their value as plant-food. Plowing might perhaps help matters, but it is very difficult-far more so than in temperate regions. In the first place, when a field is newly cleared the roots and stumps prevent plowing. If the field is left until the stumps have rotted, new plants grow up to such an extent that a fresh clearing is necessary, and the process of plowing is still very difficult. At the end of the first year after an ordinary field has been sown, plowing is out of the question except where the most advanced methods are available, and it is of no use to burn the fields over and plant a new crop, for the returu will not justify the labor. Hence, after one cultivation, fields must be allowed to lie fallow for about four years. During this period the bushes grow to a height of ten to twenty feet, according to the amount of rainfall, and the ground recovers its vitality. Then the bushes are again cut and allowed to dry, and when the land has been burned off a good crop may be raised. Evidently the clearing and burning of the bushes are essential parts of agriculture. If the dry season is long, this process is easy, for three weeks of steady sun suffice to dry all but the larger trunks sufficiently so that they can be burned. If showers fall every day or two, however, the trees and bushes have little chance to dry. This happened in 1913 in Guatemala, and I saw many fields where the 
vegetation had been cut but could not be burned. After the dry season was over, it was useless to attempt to burn the brush, for even if it had been dry enough the new vegetation, which had instantly sprung up, was sufficient to prevent burning. Without burning, it would have been useless to plant corn, for the native vegetation would have strangled it. Hence in many cases the people raised no corn crop that year.

Conditions of this sort prevail not only in large parts of Central America, especially on the east side, but throughout much of the Amazon Basin. Just how large the area is, it is impossible to say, but probably 2,000,000 or more square miles is no exaggeration. In all this region, then, it has hitherto been practically out of the question to clear the forest and get it dry enough to burn. Hence agriculture has been impossible, and will remain so until the white man introduces wholly new methods. This he will doubtless do, but the task will not be easy. I would emphasize once more that although the white man has shown himself able to raise bananas and coffee on the borders of the moist tropical areas he has not done so in the worst portions. Moreover, he has devoted himself to special erops which yield a large return in proportion to the labor, and which do not have to be planted every year. They will always be important as luxuries, or even necessities, in northern countries, but they cannot be the primary food crops of a dense population. The primary crops, for the most part, must be planted each year, and this involves the plowing of the land, or else the cutting and burning of the bushes in order to give the sceds a chance. This can of course be done if suffieient effort is expended, but the fact remains that throughout a large part of tropical South America the task is so difficult that neither the white man during the past four hundred years, nor the native races during thousands of years, ever seem to have accomplished it in such places as the great Amazon Basin.

Before passing on to more important matters mention should be made of another factor which prevents people from living permanently in certain portions of the tropies 
and from developing a high civilization. The difficulty in this case arises from the unequal distribution of the rainfall during the various seasons of the year. For instance, portions of the vast grassy plains, or Llanos, of the Orinoco Valley are almost impassable at certain seasons, because they are flooded by the heavy equatorial rains. Yet, during the long dry season, which here prevails during our winter months, those same plains become so dry that in many places it is impossible to get water except by digging deep wells. The difficulties which here confront agriculture are so great that the native races have never succeeded in surmounting them. In fact before the introduction of cattle, agriculture was quite impossible for another and wholly different reason. There was no means of breaking up the sod, which is an essential prerequisite, if crops are to be raised. Even the white man has found agriculture so difficult that he has rarely attempted it, and has utilized the plains only for cattle raising. This also is beset with many difficulties, because of the superfluous supply of water and mud at some seasons, and the drought at others. In still other regions, although a fairly dense growth of jungle covers the ground, the water supply presents a serious difficulty, for during the long dry season most of the springs disappear; hence deep wells are necessary and these are a difficult matter for primitive people, not well equipped with iron tools. This, it is true, has little direct influence upon the white man, but indirectly, as we shall soon see, it adds its quota to his difficulties.

The fact that in large portions of tropical America it has thus far been impossible for any large number of people to obtain a living has most important consequences in more favored regions. Among the factors which most promote progress, the intercourse of race with race holds a highly important place. Even the most active and energetic community is likely to stagnate if left to itself. In tropical regions the conditions which have just been described render intercourse peculiarly difficult. Where vast areas are uninhabited because of dense forests and the consequent difficulty of agriculture, and others because of floods and excess 
of water on the one hand, or the long dry period on the other hand, it is clear that the places where people can live are likely to be very much scattered. The dense forest is almost impassable. It is usually the haunt of dangerous wild beasts, and it presents a barrier quite as effective as lofty mountains or sandy deserts. The swamps and mud due to excessive floods are not quite such serious barriers, since they disappear during the dry season. Even then, however, difficulties arise, for the distance from water to water is often great, and there are no villages where food and shelter can be obtained. Thus intercourse is hindered not only by mountains, seas and the ordinary obstaeles which play a part in the temperate zones, but by other and even more efficient obstacles. Hence the primitive inhabitants of tropical America have had little intercourse with one another, and have not had the advantage of the eonstant stimulus derived from contact with new ideas and habits. This would seem to be one of the important reasons why the people of the tropies have remained backward. Even today it is producing important results. Wherever white men have settled in tropical America they are isolated. Peru, for instance, has little communication with the rest of the world; the same is true of Ecuador and Colombia, and, to a less extent, of Venezuela. This is partly due to their mountains, but far more to the fact that the great plains to the east of them are even now practically impassable. If the plains of the Amazon Basin were as easily crossed, and as densely inhabited as the plains of Illinois and Iowa, Peru would be almost as mueh in touch with the rest of the world as is California.

Thus far we have spoken of some of the handicaps which apply to primitive people, but which can ultimately be overcome by energetic races of northern origin. There is one way, however, in which for a long time to come these conditions will act as a handicap even to the Northerners. Partly because of them, and partly for other reasons, the native inhabitants of Central and South America, that is, the Indians, are very backward. 'They are dull of mind and slow to adopt new ideas. Perhaps in the future they 
will change, but the fact that they have been influenced so little by four hundred years of contact with the white man does not afiord much ground for hope. Judging from the past, there is no reason to think that their character is likely to change for many generations. Until that time comes they will be one of the white man's greatest obstacles. Experience in all parts of the world shows that the presence of an inferior race in large numbers tends constantly to lower the standards of the dominant race. This can scarcely be emphasized too strongly. Here in America we know to our cost that the presence of the negro, even though he forms only a ninth part of the population, is one of our gravest problems. If he could be eliminated from the southern states, their future would be much brighter than is now the case. Yet they are not so great a handicap, apparently, as the native races of Central and South America. Whatever the negro may have been when he was first brought to America, he is certainly now far less stolid and indifferent, far more subject to stimulating influences than the Indians of tropical America. It is literally true in Guatemala, for instance, that the more an Indian is paid the less he will work. If one day's pay will buy two day's food, he will work half the time, if the pay is increased so that one day's pay will buy food for three days, he will work one-third of the time. The experiment has been tried again and again, and there is practically universal agreement as to its result. The most considerate employers of tropical labor agree with the most inconsiderate in saying that in general it is useless to attempt to spur the Indians by any motive beyond the actual demands of food and shelter. Kindness and consideration on the part of the employer undoubtedly promote faithfulness, but they seem rarely to arouse ambition or energy. With the negro, as everyone knows, somewhat the same condition prevails, but by no means to so great an extent. In Central Amcrica, for example, it is generally thought that a negro from Jamaica is somewhat more efficient than an Indian, while a negro from the United States is much more efficient. The negro in the United States is generally considered to be more efficient than he was in 
Africa, whereas the Indian of tropical America, staying in his old environment, does not seem to have changed. Doubtless the change in the negro is due to a new social environment quite as much as to a new physical environment, and many authorities believe that the change in social environment is vastly the more important of the two. This, however, does not materially alter the case. As conditions are now, it is manifestly impossible to change the physical environment of the Indians so long as they remain in their present habitat, and it seems to be extremely difficult, also, to change their social environment. Those who dwell permanently in the white man's cities are influenced somewhat, but here as in other cases, the general tendency seems to be to revert to the original condition as soon as the special impetus of immediate contact with the white man is removed. I think we may fairly say that this has been the case almost everywhere within twenty degrees of the equator. Here again I would not be understood as saying that it will necessarily continue thus, but merely that the process of change is bound to be very slow. The aborigines show no sign of disappearing, or of being swallowed up by a multitude of immigrants, as has been the case in temperate latitudes. On the contrary there appears to be a general impression that in the equatorial countries of Latin America the proportion of Indian blood is increasing at the expense of the pure white. This is because the white man, except perhaps in a few favored places, suffers from tropical diseases far more than does the native, and unless he is wise enough to adopt the latest discoveries of medical science his children die or grow up weak. It is notoriously true that in India there is almost no such thing as a fourth generation of Indian-born British. The original stock is so weakened by tropical conditions that the children must either be sent back to Europe to recover their health, or else they become enfeebled and their descendants soon die out. Even with the help of modern medical science, it is far from certain that the number of permanent white inhabitants of the tropics can increase greatly, and there is reason to think that that same medical science may do much to prevent 
the death of children among the natives, and may thus gradually increase their numbers. Such an increase of the natives has already occurred in India, not so much because of the conquering of diseases, as because of the prevention of famine.

If the conclusion just reached is correct, we seem to be justified in the further conclusion that for a long time to come tropical America will contain a dull, unprogressive Indian population. The presence of such a population will constantly expose the white man to a most deteriorating influence. For example, the inferior mental ability of the lower race, and its incapacity for effective organization is almost sure to lead to the abuse of its labor and to its exploitation in some form of peonage, even though the fact may be disguised by legal phraseology. Again, the presence of a despised race, which cannot easily retaliate when imposed upon, is almost certain to lead to low sexual morality. In the same way, political equality is almost certain to become a mere form of speech, for the dominant race will not permit the other to gain rights at its expense. Manual labor, too, will be despised, for it will be associated with the idea of an inferior race. All these things may be looked upon as disadvantages of the lower race rather than of the higher, but $I$ believe that the higher race reaps by far the greater injury. The conditions which have just been mentioned. appear to be among the most potent factors in rendering it difficult for the white man to attain as much success in tropical regions as in those farther to the north or south. Their evil effect is roughly proportional to the difference between the two races. That difference is at a maximum where a low tropical race remains in its original, unstimulating environment, and is brought in contact with immigrants of a highly developed race who completely change their environment. The newcomers are released from old restraints at the time when they come into contact with conditions which make a peculiar demand for exactly those restraints. Hence, instead of being stimulated to greater political freedom and equality, sterner morality, and more intense industry, as was the case among the settlers in New 
England, the immigrants who come from the North to tropical America are in danger of being weakened in all of these respects. The effect on the original immigrants is bad enough, but on their children it is far worse. The settler, or European colonist, possessed of wealth and power, can to a slight degree shield his children from the deteriorating influence of the natives, but even in such cases children are in constant contact with servants. They grow up with a supreme contempt for the natives, and at the same time with the feeling that they can treat them as they choose. If poorer people, that is, colonists in the ordinary sense of the word, attempt to live in the tropics in large numbers, especially if they are people who work with their hands, their children are exposed still more to all the contaminating influences of contact with the natives. Hence the second and third generations, and the fourth and fifth, if there are any, suffer more than their ancestors.

Thus far we have been dealing with external handicaps; that is, with those which may have an important effect upon the white man, but which are outside him. Let us turn now to others which touch him more vitally. The first of these is tropical diseases. This subject has been so much discussed that I shall here refer to it only briefly. There can be little doubt that malaria, and the many other diseases which are characteristic of tropical countries, have much to do with the low state of civilization in those regions. The old idea that the people who live in tropical regions are immune to local discases is no longer accepted by students of tropical medicine. Adults, to be sure, are often immune, but apparently this not true of the race as a whole. Vast numbers of children die in infancy and early childhood from the same diseases which prevent the white man from permanently living in the tropics. Other's suffer from the diseases, but recover. 'They bear the results with them to the grave, however, in the form of enlarged spleens, or other grave injuries to the internal organs of the body. The world has of late years been astonished at ravages of pellagra and other diseases due to such organisms as the 
hookworm. We have found that people who are subject to them cannot be highly competent. Their mental processes, as well as their physical activity, are dulled. So long as a community is constantly afflicted with such disorders, there is little hope that it can rise high in the scale of civilization. All this is now universally recognized, and need not here be further amplified. Nothing is more hopeful for the tropics than the rapid progress which has been and is being made in the control of these diseases. If they could be eliminated, not only would the white man be able to live permanently where now he can be only a sojourner, but the native races would probably be greatly benefited. How great this benefit would be we cannot yet tell, but it is highly probable that the elimination of the diseases which especially affect children in the tropics would do much to increase the vitality, energy and initiative of the native races. This in itself would be an immeasurable boon not only to the natives themselves, but to the white man, who would thereby be freed in part from some of his worst social dangers.

This highly desirable result cannot be obtained quickly. We hear it said sometimes that the achievements of the United States in Panama prove that diseases can be eliminated anywhere in tropical countries. This is true, but it must be remembered that Panama is a highly specialized case. During the building of the Canal a great number of people were collected into a small area, and enormous sums of money were freely expended. Everyone, too, was subject to strict, semi-military rule, and similar conditions will presumably continue under civil rule. Such methods cannot be applied to millions of square miles. The expense would be absolutely prohibitive. The ordinary farmer in tropical regions cannot expect to be protected by his government. He must protect himself. In the long run even tropical races may learn to do this, but it will be a difficult and expensive matter, and will require a radical change in the people themselves. That change will doubtless come, but not for generations, and not until a long selective proc- 
ess has gone on whereby those who do not adopt modern medical methods for preserving health will be gradually eliminated, while those who adopt them will persist.

We now come to what seems to be the most important portion of our subject. It is likewise the portion as to which we must speak with the most hesitation. We may hope that the white man will ultimately cultivate the forests, traverse the waste places, elevate the native races, and conquer the diseases of the tropics, but will he do this as a genuine colonist, or as an outsider whose mind is always full of the idea of getting back "Home?" The answer depends largely upon the extent to which he can permanently retain his physical, mental, and moral vigor-not merely for a few years, but for generations. Hence we are led to inquire whether aside from the specific diseases which can be eliminated, there is anything in a tropical climate which prevents a vigorous development of civilization. I realize that in entertaining this possibility I am going counter to the opinion of practically all anthropologists, and I am not at all confident that $I$ have reached a final solution. All that I can do is to present certain facts which have lately been discovered, and show what seem to be their logical consequences. These facts seem, at first sight, most discouraging. They apparently indicate that even though the diseases of tropical regions be overcome, northern races cannot there be as efficient as they are in their own habitat. In hot climates man appears to be handicapped by a definite lowering not only of his physical energy, but of his mental activity and moral vigor. I would hasten to add, however, that this does not mean that this inhibition of activity cannot be counteracted. It may perhaps be no more formidable a handicap than are tropical diseases, although its elimination will probably not take place so quickly.

Before coming to the causes of such a climatic inhibition, let me call attention to one of the most notable and regrettable effects of a tropical environment. This is the lack of will power which is almost everywhere displayed by a large proportion of the northerners who come to equatorial regions. 
It manifests itself in four special ways, namely, in relative lack of industry, in an irascible temper, in drunkenness, and in sexual indulgence. For the present we are not concerned with whether these things are due to physical or social environment. Doubtless the two work together. The point upon which to fix attention is that for some reason self-control, which is merely another name for will power, seems to diminish among practically all people who go to tropical countries.

In the amount of work accomplished, that is, in the quality known as industry, the difference between people in tropical and other climates is very noticeable. Practically every northerner who goes to the torrid regions of America says at first that he works as well as at home, and that he finds the climate delightful. Little by little, however, even though he retains perfect health, he slows down. He does not work so hard as before, nor does the spirit of ambition prick him so keenly. If he is on the low, damp seacoast, the letting down process is relatively rapid, although its duration may vary enormously in different individuals. In the dry interior the process is slower, and on the high plateaus it may take many years. Both in books and in conversation with inhabitants of tropical regions one finds practical unanimity as to this tropical inertia, and it applies both to body and mind. After long sojourn in the tropics it is hard to spur one's self to the physical effort of a difficult mountain climb, and it is equally hard to force one's self to think out the various steps in a long chain of reasoning. The mind, like the body, wants rest. Both of them can be spurred to activity but the activity exhausts one's vitality. When we come to the explanation of this well recognized inertia, however, there is much divergence of opinion. One man will say that within the tropics the northerner does not need to work so hard as farther north, because salaries are higher; another says it is because servants are cheap; still another claims that hard work is dangerous to the health, and almost all agree that "anyhow one doesn't feel like working down here." Probably all four of these factors coöperate and each, doubtless, produces pronounced 
results, but the last two, that is, health and "feeling," seem to be the most important when many generations are taken into account. In spite of individual exceptions, it seems to be generally true that white men who spur themselves up to work as hard within the tropics as they do at home are in great danger of breaking down in health. They become nervous and enfeebled, and are likely to succumb to some of the many tropical diseases. This is one of the most powerful deterents to the development of an efficient white population in tropical regions. If the more energetic members of the community ruin their health, they are pretty sure to die before their time unless they go back to the north. Thus if white colonization takes place on a large scale in tropical America there is grave danger that the less energetic elements will be the ones to persist and to become the ancestors of the future population. The other factor, the feeling of inertia, may perhaps be interpreted by teleologists as a merciful provision of Providence to warn the white man that he must not work too hard in the torrid zone, but that will scarcely help to advance civilization. Few people will question the reality of the tropical inertia. It is the same lassitude which every one feels on a hot summer day - the inclination to sit down and dream, the tendency to hesitate before beginning a piece of work, and to refrain from plunging into the midst of it in the energetic way which seems to be natural under more stimulating conditions.

Lack of will power is shown by northerners in tropical regions not only in loss of energy and ambition, but in fits of anger. The English official who returns from India is commonly described as "choleric." Every traveler in tropical countries knows that he sometimes bursts into anger in a way that makes him utterly ashamed, and which he would scarcely believe possible at home. Almost any American or European who has traveled or resided in tropical America will confess that he has occasionally flown into a passion, and perhaps used physical violence, under circumstances which at home would merely have made him vexed. This is due apparently to four ehicf causes. One of these is the 
ordinary tropical diseases, for when a man has a touch of fever, or of some other illness, and is afraid that he is in for a long siege, his temper is apt to get the better of him. In the second place, the slowness of tropical people is terribly exasperating. The impatient northerner uses every possible means to make the natives hurry, or to compel them to keep their word and do things according to their promises. His energy is usually wasted - the natives do not seem to be influenced at all, and the only visible result is an angry and ridiculous foreigner. Yet there are of ten circumstances where a show of anger and violence seem to be the only ways of getting things done, and this is frequently used as an excuse for lack of self-control. A third reason for choleric temper is found in the fact that the consequences of becoming angry are less dangerous than elsewhere, because the inert people of tropical America often submit to indignities which an ordinary white man would bitterly resent. Of course they resent ill treatment, and will retaliiate if possible, but they generally do not have sufficient energy or cunning to make their vengeance effective against the powerful white man. Finally, those who have lived in the tropies generally find that, even when things go quite smoothly, and when they are in contact with people of their own kind and are in comparatively good health, they are on the whole more irritable than at home. In other words, their power of self-control is enfeebled. Of course there are many exceptions, but that does not affect the general principle.

Drunkenness, our third evidence of lack of self-control, need scarcely be discussed. The white man's alcohol in the form of rum is scarcely more injurious to the natives of Africa than is his alcohol in other forms in tropical America. In most portions of Central America the highly intoxicating drink known as "Agua ardiente" ("white-eye"), can be procured very cheaply. In some places, such as Guatemala and parts of Mexico, where I speak from personal experience, drunken men and women may be seen upon the streets at almost any time of day. Nowhere else, during extensive travels in America, Europe and Asia, have I ever seen so 
much drunkenness as in Guatemala. Among the white men who go to tropical America a large number drink as badly as do the natives. Various causes for this can readily be seen. The drunkenness of the natives is partly due to the cheapness with which strong intoxicants can be prepared from the lees of sugar, or other sources. That of the white men arises partly from the constant heat which makes people want something to drink at all times, partly from the monotony of life, and still more from the absence of the social restraints which exercise so powerful an inhibitory influence at home. Back of all these things, however, among both the white men and natives, there seems to lie a certain enfeeblement of the will which may be closely connected with the physical inertia which prevents people from working hard, and with the lack of self-control which manifests itself in bursts of anger.

The last of the ways in which weakness of will is evident in tropical America is in the relation of the sexes. Upon this rock a large number of northerners are wrecked. It is due partly to the low standards of the natives themselves, partly to the mode of dress among the women, which constantly ealls attention to their sex, and partly to the free open life which naturally prevails in warm countries. In addition to this there seems to be another reason. Either the actual temptation to sexual excess is greater than elsewhere, or else the inhibitory forces are weakened by the same effects which cause people to drink, to become angry, and to work slowly. Perhaps the matter can best be illustrated by a remark of a missionary of a small and extremely devout sect, a most austere man, whose whole soul was devoted to preaching the gospel. Speaking of Central Ameriea in general he said: "When I am in this country evil spirits scem to attack me. I suppose you would call it something else, but that is what I think they are. When I am at home in the United States I feel pure and true, but when I come here it seems as if lust was written in the very faces of the people." His experience is that of practically all northerners. The evil effects of undue sexual indulgence need not be discussed. I shall merely refer to 
a remark of Gouldsbury and Sheane, in their authoritative book on the Great Plateau of Rhodesia. They hold that one of the chief reasons for the backwardness of the people of Rhodesia is that so large a part of their thought and energy, especially in youth, is swallowed up in purely sexual matters.

The serious evils mentioned in the preceding paragraphs, that is, a diminution of energy, outbursts of temper, drunkenness, and immorality, are ascribed by many people to social causes. I recognize the importance of this view and largely concur in it. Nevertheless, consideration of some statistics which I have recently compiled suggests that physical causes may play an equally important rôle. Two years ago, at a conference on Japan, corresponding to our present conference on South and Central America, I briefly mentioned certain investigations on the effect of different climatic conditions upon human activity. The problem which then presented itself was to make actual measurements of the effect produced by different climates. Obviously it is impossible to do this directly. It might, of course, be possible to measure the efficiency of two similar groups of people of the same race, age and general status, under different types of climatic conditions. The results, however, would be absolutely inconclusive. It would be impossible to determine whether any differences which were discovered were due to original differences in the people, to differences in their food, or to a hundred other variable factors. Another possible test would be to take a given group of students, for example, whose homes were, let us say, in southern Texas, but who were studying in the north. They could be tested while living in the north and again in the south, but here again the results would have little value, because the change from one place to the other would in itself create a difference in the minds of the subjects. It would also be practically impossible to make sure that their diet, occupations and general environment, aside from the matter of climate, were the same in both cases. After due consideration of these matters, the only practicable test, for the present at least, seems to be to take a group of 
people-factory hands, for instance-and compare their efficiency from day to day. Their social environment, food and mode of life remain unchanged. Aside from changes in factory management, and other similar matters for which proper allowance can be made, the only changes which influence all the members of such a group are those connected with the weather, or with the coming of Christmas, or similar seasonal occurrences. By choosing people who are doing piece work which is recorded day by day, it is possible to determine the relative efficiency on days of any given temperature, or on damp days, windy days, and so forth. When such data are properly compiled they show how people would behave under all sorts of climatic conditions.

In pursuance of this object I have obtained the statistics of about 500 people for each day during the year. They were piece workers in factories in southern Connecticut, partly men and partly girls. In order to combine mental and physical work, I have also, through the courtesy of Professor Cattell of Columbia University, obtained figures for tests of three children upon the typewriter. The tests extended over a period of two years. They were made daily during the first year, and weekly during the second. A third line of evidence, purely mental consists of the daily marks of fifteen hundred students at the Military Academies at Annapolis and West Point. Thus we have tests of both physical and mental activity. Both types show the same phenomena. I do not here propose to discuss the results in detail, for they are embodied in a series of articles in Harper's Magazine and in a volume, entitled The Distribution of Civilization, shortly to be published. I shall mercly give one or two conclusions.

The first and most important conclusion is that in spite of man's boasted independence of climate by reason of fire, clothing, and houses, he is influenced by the outside temperature in much the same way as are plants and animals. Biologists have long known that every species of plant grows best at what is termed its "optimum" temperature. Growth begins at a temperature a few degrees above freezing, but is then very slow. As the temperature rises the rate of growth 
increases, slowly at first, then rapidly, and finally slowly once more until the optimum is reached. Then, if the temperature rises still higher the rate of growth begins to decline and soon falls off very rapidly.

Recent studies seem to show conclusively that animals are influenced by temperature in the same way as plants. In the case of the crayfish, for example, the matter has been investigated with great care. The curve of activity of such an animal closely resembles that of plants, although of course the optimum temperature varies according to the species. The method of investigation consists in measuring the amount of oxygen consumed in a given time at a given temperature, or the amount of carbonic acid given off. Other chemical reactions of the body have also been examined with similar results. The whole subject is in its infancy, but certain facts are already clear. The activity of an organism is closely related to the speed with which oxidation takes place, and the completeness and rapidity with which waste products are removed from the body. At low temperatures plants and cold-blooded animals cannot grow rapidly or be very active, simply because the various chemical processes of life cannot take place fast enough. As the temperature rises these processes all become more rapid, and the organism exhibits greater energy which manifests itself either in movement or in the laying on of new tissue. This continues until a point is reached where the chemical processes take place so fast and break down the tissues so rapidly that it is physically impossible for the organism to get from the air enough oxygen fully to oxidize the broken down materials. Unless these are oxidized they are not easily eliminated. Hence they accumulate in the body, and apparently act almost like poisons. As soon as this occurs the activity of the organism declines, and there is a correspondingly smaller necessity for oxygen. Thus a certain amount of oxygen is left unused by the fundamental life processes, and is available to oxidize and remove the injurious waste materials which have begun to accumulate. If an organism, because of strength of will, fear of enemies, desire for food, or some other stimulus, is unduly active at 
high temperatures, it lays up within its own body a store of unoxidized and unexcreted waste materials which either lead to death, if the unfavorable conditions continue, or else necessitate periods of the least possible activity in order that nature may restore the disturbed balance. The whole matter is too complicated to be explained in detail, and it needs far more extensive study on the part of biologists. We do not yet know how the effects of temperature upon warm-blooded animals compare with those observed in cold-blooded animals and plants. Nevertheless the striking resemblance of the curves of physical activity of factory operatives and of mental activity of students, on the one hand, to the curves of plant growth and of physiological activity among lower animals, on the other hand, suggest that a close relationship between temperature and activity is a universal biological law.

For the people thus far tested, practically all of whom were descendants of the more progressive nations of northwestern Europe, the temperature of greatest physical efficiency is $59^{\circ}$ or $60^{\circ} \mathrm{F}$, while for mental activity it may be somewhat lower. This conclusion is especially important because of the large number of people involved. It agrees with some results obtained by Lehmann and Pedersen in Denmark on the basis of three individuals. The fact that even when only a few individuals are tested, the relationship is apparent shows how universally the same law applies. The optimum temperature may vary according to the individual and according to the race, but the amount of variation is probably only a few degrees, and it makes no difference as to our present conclusions. The common idea that we are most active in cold weather is deceptive. To be sure, we are active when we are out in the cold, because we must keep warm, but the actual amount of work accomplished in winter is much less than in the spring and fall. Low temperature, however, does not seem to produce such lasting effects as does warm. It may cause the body to burn up its materials too fast, but it does not load it with harmful unoxidized waste, or in some other way inhibit activity. This apparently is why tropical 
peoples have rarely been characterized by great achievements, and why the white man today is less efficient in the tropics than elsewhere.

In the lowlands of tropical America the temperature is everywhere above the optimum. This means that there is no escape from unfavorable conditions, and that the inhabitants of that region, no matter what their race, cannot be expected to be active in body and especially in mind, or strong in will so long as present conditions continue. This, however, is by no means the whole story. The work done by factory hands and others in Connecticut shows that another climatic element is of vital importance. In all the cases examined it was found that while the mean temperature is the most important of the climatic factors, the change of temperature from one day to the next has an influence which cannot be ignored, and which may be almost equally great. If the temperature today is the same as yesterday, people work comparatively slowly. If the temperature today is higher or, more especially, lower than yesterday, people are stimulated, and the stimulus is almost proportional to the amount of change. The only exception is that an extreme change appears to be too much, and does not produce proportionate results. The way in which the stimulus acts may be illustrated by a simple comparison. Consider the difference between the amount of ground covered by a horse that is allowed to go his own gait and by one that is gently urged at proper intervals. If the animal is constantly but slightly urged-as man would be by a temperature which is highly favorable, but which never changes - he will go fairly fast, but will at length become exhausted. If he is somewhat urged, however, and then allowed to go more slowly, and then urged again, he will cover the ground faster than if allowed to go his own jogging gait, and he will require less time for rest because he will be less exhausted. Apparently this is what happens to mankind in temperate regions. Change from season to season stimulates him, and then lets him fall back to a slower pace; change from day to day has the same effect, but on a smaller scale. Hence he is kept up to his work, 
and therefore accomplishes much. In tropical America just the opposite happens. The mean temperature throughout most of the lowlands is above $80^{\circ} \mathrm{F}$. Therefore the amount of accomplishment must be relatively small. This, however, is by no means the worst feature. Far more injurious is the fact that even in the mountains where the mean temperature often falls to a favorable level there is no appreciable seasonal stimulus, and no daily changes such as accompany our storms. Therefore the human horse gradually drops to a low state of efficiency. This is not mere theory -it is simply a logical application of what actually happens every year among the people of Connecticut and other parts of the eastern United States. If those people were put into a tropical environment, and all other conditions of their environment remained exactly the same as at present, their efficiency would drop greatly. By special effort they might remain for a time not far below their present level, but special efforts cannot last year after year without exhausting people's vitality. Whether the decrease in efficiency would be 10 or 50 per cent we cannot yet determine, but it is safe to say that it would be large. Nor is the mere decrease in physical activity the most important feature of the case. Since common experience shows that as a rule our minds work best when our bodies are in good health, and since our investigations show that physical and mental work are influenced in essentially the same way, it follows that the high temperature and lack of change in tropical America presumably weaken the power of man's mind. This, perhaps, accounts for the fact that almost no great ideas have ever been born and perfected within the tropics. The same sluggishness of mind which prevents the faculty of invention from being highly developed may account for the lack of will power which seems to be the greatest of all tropical handicaps.

Taken as a whole the results which have just been set forth seem at first sight most discouraging. They seem to imply that although the white man, coming temporarily as a sojourner, may overcome the physical obstacles of tropical America, and may learn to protect himself from tropical 
diseases so that he can dwell there permanently, he must apparently face the fact that his vitality and, still more, that of his children, will inevitably be depressed. He will not be able to work as he did in more northern climates, and he cannot have the self-control and mental activity which he there possessed. He goes to the tropics with an inheritance vastly better than that of the aborigines, and this will stand him in good stead for many generations, but yet in the end his lot seems no better than theirs, for if he stays there permanently, he is in serious danger of slipping slowly backward, simply because he cannot make the strenuous exertions by which people in more favored regions are continually going on to some new achievement.

This discouraging view is by no means justified. It is like that of the poor laborers who went about in mobs to break up machinery when the steam engine was first introduced. They thought that machinery was taking the bread from their mouths. They little realized that it would put into the hands of their children hundreds of things which in their own day were possible only for the rich. The view of South America here presented is in reality extremely hopeful. Everyone recognizes that tropical regions are backward, and that, in spite of all our optimistic talk, we have made almost no progress toward any permanent occupation or development of millions of square miles of what are probably the most productive regions in the world. We must frankly face the fact that even the little progress which has been made in recent decades is almost entirely the work of men from the north, and that generally the important things are done by the first generation, or else by people of later generations whose lives have in good measure been spent in more favored regions away from their tropical homes. Four centuries ago the world stood face to face with the wonderful opportunity of a new world. For a hundred years almost nothing was done in the way of permanent colonization. Except for a few Spanish colonies Europe was content merely to explore and exploit. Then the temperate regions of North America began to be settled, and to grow great, and later their example was followed 
by the temperate lands of South America. Today our attitude toward the less favored tropical portions of South and Central America is almost like that of Europe toward America as a whole three hundred years ago. In $1600 \mathrm{~A}$. D. not a single successful colony had been established in what are now the most successful parts of the New World. That fact might then have seemed as discouraging as does our present lack of success within the tropics.

The comparison that has just been made does not quite cover the real conditions. We might better compare ourselves with a primeval group of naked, fireless, houseless savages who want to inhabit a land where the winters are long and cold. Such men would say that while an occasional man, hardier than his fellows, might stay in such a land through the winter, and while it might be possible for many people to go there in summer, permanent occupation of the country was absolutely out of the question. This view would not be at all unreasonable. Yet if some happy accident led one of the savages to discover how warm a man might be when he stripped the hide from a bear and threw it around himself, how quickly there would be a change of opinion. When fire became known opinion would change still more. And when some lucky genius discovered that a man could pile up stones or sticks and cover them with mud or skins or grass and thereby form a house which would keep out rain, snow and wind, and within which a fire could be made, would not the whole tribe laugh at their former lack of faith? Or rather would not each one say that he had always expected some such thing, and that he was on the very point of making a bearskin coat, inventing a house and discovering fire when someone else got ahead of him?

Today we are like these savages. We have long recognized that there is some fatal influence which has kept tropical regions from developing on a par with temperate regions. The vast majority of us believe that this is due to climate. Our trouble has been that we have not understood exactly how climatic influences work. We have not known whether they actually cause the human mind to deteriorate, or 
whether they merely hinder its development. We have not known whether the white man can live and thrive in the tropics, or whether he must inevitably deteriorate. Only one thing has been clear, namely, that the most obvious tropical hindrance is the terrible prevalence of disease. This we have attacked, and our final success can scarcely be doubted, although there is a vast amount still to be done. We have reached the position of the savages after they discovered the use of clothing, but before they had learned to use fire and houses. Our next task is to find out more precisely how temperature and changes of temperature, together with humidity and other climatic factors, affect the human system. We must measure all sorts of physiological and psychological functions in terms of these factors, and we must be able to work out the exact measure of the influence of any given type of climate. Then we shall be ready to search for remedies. Perhaps we shall devise some means of varying our supply of oxygen. Possibly we shall give the people of tropical regions the necessary variety of climate by moving them in wholesale fashion from the mountains to the plains and back again at short intervals. Possibly we shall devise a plan whereby some means of creating the stimulus which now comes from the optimum temperature and from frequent changes shall be as much a part of a tropical house as a stove or furnace is a part of a house in regions with cold winters. All these are vague suggestions, but they indicate the sort of things that may perhaps be done. The future of South America depends largely on our success along these lines. We have conquered low temperature in large measure. Our next great task is to conquer the uniform heat of the lands within the tropics. 

THIS BOOK IS DUE ON THE LAST DATE STAMPED BELOW

AN INITIAL FINE OF 25 CENTS WILL BE ASSESSED FOR FAILURE TO RETURN THIS BOOK ON THE DATE DUE. THE PENALTY WILL INCREASE TO 50 CENTS ON THE FOURTH DAY AND TO \$1.00 ON THE SEVENTH DAY OVERDUE.

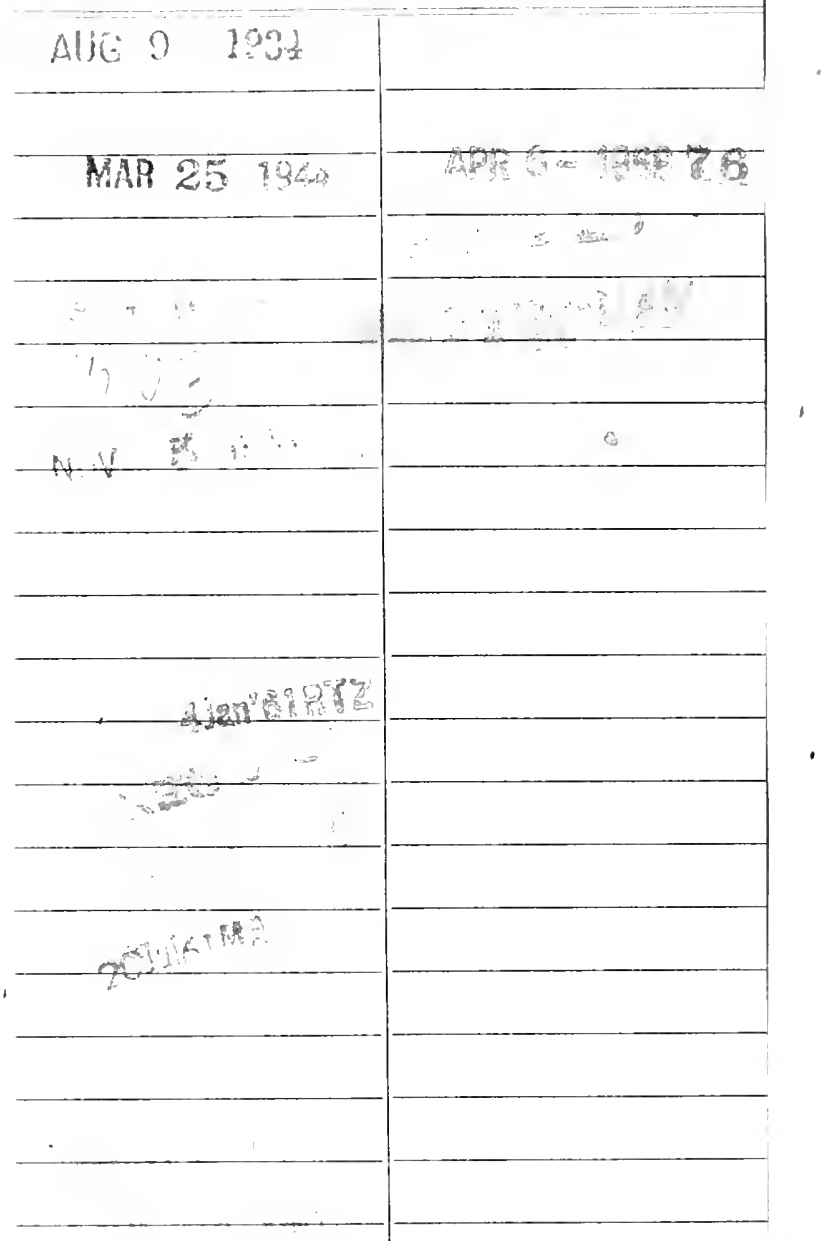

ILI) $21-100 m-7,33$ 


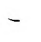


. 
